\title{
APROXIMAÇÕES ENTRE O TURISMO E A RESILIÊNCIA: UM CAMINHO PARA A SUSTENTABILIDADE
}

\author{
LINKING TOURISM AND RESILIENCE: AN ALTERNATIVE ROUTE TO SUSTAINABILITY
}

\section{APROXIMACIONES ENTRE EL TURISMO Y LA RESILIENCIA: UN CAMINO PARA LA SOSTENIBILIDAD}

\author{
Kerlei Eniele Sonaglio \\ Professora na Universidade Federal do Rio Grande do Norte (UFRN), \\ Doutora e Mestre em Engenharia Ambiental (UFSC), \\ Bacharel em Turismo (ASSESC), \\ kerlei@ufrnet.br
}

Data de Submissão: 16/03/2017

Data de Aceitação: 25/10/2017

RESUMO: Neste estudo de aproximação entre o turismo e a resiliência se expõem a origem e os significados que esta última assumiu em tempos contemporâneos. Além disso, reflete-se sobre como as metodologias que examinam o comportamento resiliente de indivíduos ou das ações resilientes no ambiente podem ser incorporadas no turismo, no fito do turismo sustentável. Então, para dar suporte às reflexões, realizou-se pesquisa bibliográfica, eletrônica e documental. Assim, visando relacionar o turismo e a resiliência, reflete-se sobre a incorporação das abordagens da resiliência (como SOBRARE e UNISDR) no gerenciamento e no planejamento do turismo sustentável.

PALAVRAS-CHAVE: resiliência, turismo, sustentabilidade.

ABSTRACT: This study of the link between tourism and resilience outlines the origin and meanings that the latter has assumed today. It reflects on how the methodologies that examine the resilient behavior of individuals, or of resilient actions in the environment, can be incorporated into tourism to promote its sustainability. To support this reflection, we conducted bibliographical, electronic and documental research. Thus, seeking to link tourism and resilience, this study reflects on the incorporation of approaches to resilience (such as those of SOBRARE and UNISDR) in the management and planning of sustainable tourism.

KEYWORDS: resilience, tourism, sustainability.

RESUMEN: En este estudio sobre la resiliencia en el turismo se exponen el origen y los significados que la cuestión de la resiliencia asumió en tiempos contemporáneos. Además, se reflexiona sobre cómo las metodologías que examinan la capacidad resiliente de un individuo o de las acciones resilientes en el ambiente pueden ser incorporadas en el turismo, en el objetivo del turismo sostenible. Por lo tanto, para apoyar las reflexiones, se realizó una investigación bibliográfica, electrónica y documental. Así, con el propósito de relacionar la resiliencia con el turismo, se reflexiona sobre la incorporación de los enfoques de la resiliencia (como SOBRARE y UNISDR, por ejemplo) en el proceso de planificación y gestión del turismo sostenible.

PALABRAS CLAVE: Resiliencia; Turismo; Sostenibilidad.

INTRODUÇÃO

\section{7 pesar dos esforços no tratamento sistêmico dado para o turismo e com a intenção de assumir os princípios firmados no Relatório Brundtland (em 1987), o planejamento e o gerenciamento do}


turismo têm revelado uma estrutura e funcionamento ineptos a assumir os ideais de sustentabilidade expressos em tal Relatório (Sansolo \& Cruz, 2003; Sonaglio, 2013, Lanzarini \& Barretto, 2014, Monge \& Perales, 2016). Isto porque o cenário capitalista, além de gerar dificuldades que visem a um desenvolvimento genuinamente sustentável, produz problemas sociais, culturais e ambientais típicos de modelos de desenvolvimento insustentáveis. Assim revela, no final das contas, que o objetivo-fim das políticas, do planejamento e do gerenciamento do modelo atual de turismo não prioriza o ideal de desenvolvimento sustentável, mas privilegia o incremento econômico (o lucro) à semelhança dos processos industriais.

Certamente que o setor operacional do turismo contribui (como produtor de riquezas) para o progresso (Lanzarini \& Barretto, 2014) e para os ideais de descentralização do gerenciamento e do planejamento turístico, pautados na sistematização do turismo no âmbito regional e local, favorecendo este processo porque propicia uma coordenação articulada e compartilhada (Hanai \& Espíndola, 2012) que o aproxima dos princípios de sustentabilidade. O turismo pode (e deve) contribuir com o desenvolvimento econômico, entretanto é preciso superar a ideia que concebe o mero crescimento econômico como sinônimo de progresso. Isto porque, mesmo diante dos dilemas e dos impasses político-administrativos perpetuados no discurso quantitativo de progresso, do crescimento econômico prioritário, da lógica do capital industrial e do mito do "desenvolvimento sustentável" (que supre as necessidades de todos e promove igualdade social, Garrod \& Fyal, 1998), é necessário profissionalizar e promover um planejamento turístico responsável (Lanzarini \& Barretto, 2014) que se consubstancie em uma atividade fundamental para os destinos gerirem o produto (para os turistas), mas que também assegure o desenvolvimento local (para os residentes e para as empresas locais) (Amorim, Umbelino \& Costa, 2013).

Assim, mesmo diante de propostas de regionalização do turismo e/ou das iniciativas que incentivem a participação de parceiros públicos, privados e do terceiro setor, a sua operacionalização, tendo em conta a organização de redes humanas locais (BRASIL, 2004, 2007), numa política de desenvolvimento regional (protagonizada em diversas localidades no mundo), constitui um avanço para o planejamento e gerenciamento turístico, mas ainda se revela insuficiente. 
Pesquisadores como Beni (1999, 2006), Solha (2006), Castro \& Midlej (2011), Sonaglio (2013), Virginio \& Ferreira (2013), Amorim, Umbelino \& Costa (2013), Lanzarini \& Barretto (2014), Silva \& Cândido (2016) têm examinado o modo como o turismo vem sendo pensado e sua repercussão nas políticas, nos planejamentos e nas gestões do turismo no Brasil, por exemplo. A partir desse exame, constataram que, apesar do modelo sistêmico em vigor, o turismo exibe e amarga severos problemas, dentre eles: falta de profissionalização; descontinuidade nas ações regionais e "cabides de empregos" vinculados a mudanças político-partidárias; despreparo das municipalidades no gerenciamento das adversidades; inexistência (ou insuficiente) de articulação entre órgãos públicos; situação precária no acesso, manutenção e fiscalização dos atrativos e dos equipamentos turísticos aliados à falha nos critérios de sua seleção para compor os roteiros regionais; falta de habilidade e competência para desenvolver um planejamento estratégico para ocasiões de crises sociais, políticas, econômicas e ambientais; baixos níveis de sustentabilidade nos destinos turísticos pela ausência ou inadequada prática de planejamento e gerenciamento das atividades turísticas e dos recursos ambientais e naturais; limitações educacionais, cognitivas, exclusão política e desinteresse da população local em participar do processo turístico; limitações do papel do estado.

Por conta disso, muitos pesquisadores têm buscado outras abordagens para subsidiar/basear seus estudos sobre o turismo, numa tentativa de compreender, interpretar e propor alternativas para um turismo mais eficiente e eficaz em seus propósitos de desenvolvimento sustentado. Isto porque o complexo cenário mundial contemporâneo vem se transformando com rapidez e os métodos para sua análise e intervenção precisam adaptar-se, ampliarem-se (Anjos et al., 2005) e/ou serem revistos. Assim, estrategicamente, o planejamento e o gerenciamento do turismo também precisam dar respostas aos atuais problemas e criar outras estratégias para garantir a sua eficiência e eficácia (Anjos et al., 2005; Melo \& Brito, 2016) no defrontamento das turbulências e das mudanças repentinas e descontínuas do ambiente externo, provocadas pela globalização, pelas inovações tecnológicas e pelo crescimento da concorrência (Porter, 1991; Mintzberg, Ahlstrand \& Lampel, 2010). 
Entretanto, para enfrentar, resistir, superar e/ou adaptar-se às adversidades do mundo contemporâneo, é preciso "resiliência" (Santos, 2009; Barbosa, 2011; Lemos, 2014; Kim \& Marcouiller, 2015) também no turismo (Becken, 2013; Luthe \& Wyss, 2014; Dahles \& Susilowati, 2015; Orchiston, Prayag \& Brown, 2016).

Para Blandtt (2009), a resiliência se apresenta como uma rota mais segura para o alcance da sustentabilidade em tempos contemporâneos. Assim, aliado aos princípios de sustentabilidade (que opera princípios como justiça e equidade), a resiliência é entendida como uma característica (Blandtt, 2009; Lemos, 2014), sobretudo nas atuações relativas ao planejamento e/ou gerenciamento turístico que precisa resistir, enfrentar, se adaptar ou superar determinados impactos das mudanças provenientes de um mundo complexo e desequilibrado.

Por conta disso, diversas instituições, entidades e governos instituíram comissões/comitês para tratar sobre a resiliência e iniciaram a utilização da abordagem resiliente nos seus documentos informativos, orientativos e explicativos. Exemplo disso é a campanha para cidades resilientes da Organização das Nações Unidas (ONU) e a plataforma para disseminar e promover um comportamento mais resiliente nas pessoas, da Sociedade Brasileira de Resiliência (SOBRARE). No turismo, o Tourism Resilience Committee, que foi estabelecido em 2008 na 84ª Sessão do Conselho Executivo da OMT/ Organização Mundial do Turismo (UNWTO) na cidade de Madri/Espanha, foi uma maneira de responder à recessão de origem econômica. Tal Comitê possui a responsabilidade de auxiliar seus membros na avaliação e na mitigação dos riscos relacionados com o turismo, como também em planejar, desenvolver e implementar sistemas de gestão de crises para reduzir o impacto e auxiliar na recuperação de crises, por meio de atividades e projetos guiados pelo disposto no Código Mundial de Ética do Turismo (UNWTO, 2016).

Na campanha da ONU, visando à Redução e aos Riscos aos Desastres, a cartilha intitulada "Como Construir Cidades Mais Resilientes: Guia para Gestores Públicos Locais" apresenta um roteiro com dez passos fundamentais para a construção de cidades resilientes e a maneira de serem aplicados (UNISDR, 2012). A prioridade expressa na referida cartilha/guia se refere à atuação governamental para reduzir os riscos vinculados aos desastres/catástrofes 
ambientais, tais como tsunamis, inundações, secas, tornados, terremotos e furacões. A campanha foi formatada para os gestores públicos objetivando apoiar decisões, preparação para implementação de ações baseadas na resiliência para reduzir os riscos a desastres.

No Brasil, até maio de 2017, 359 municípios aderiram à campanha (Figura 1) da ONU e, até então, o país possui o maior contingente de inscritos nesta campanha mundial, que recebe adesões continuamente (UNISDR, 2017). Por conta disso, o Ministério da Integração Nacional (MIN) empenha-se na busca por mais coordenação entre as unidades federativas, bem como o ajustamento à campanha a partir da espera pública federal. Isto porque, embora o Brasil conte com o mais expressivo contingente de cidades inscritas na citada campanha, apenas a inscrição não significa que o município já se tornou resiliente. A inscrição sinaliza que a cidade se comprometeu em edificar a sua resiliência por meio da definição de ações e prioridades na área da gestão de risco a desastres em sua localidade. Portanto, para o MIN, o aumento no quantitativo de cidades brasileiras inscritas sugere a "ampliação do nível de conscientização e da percepção de riscos pelos gestores locais", porém é preciso definição e cumprimento de ações na área da campanha.

Figura 1: Participating Local Government

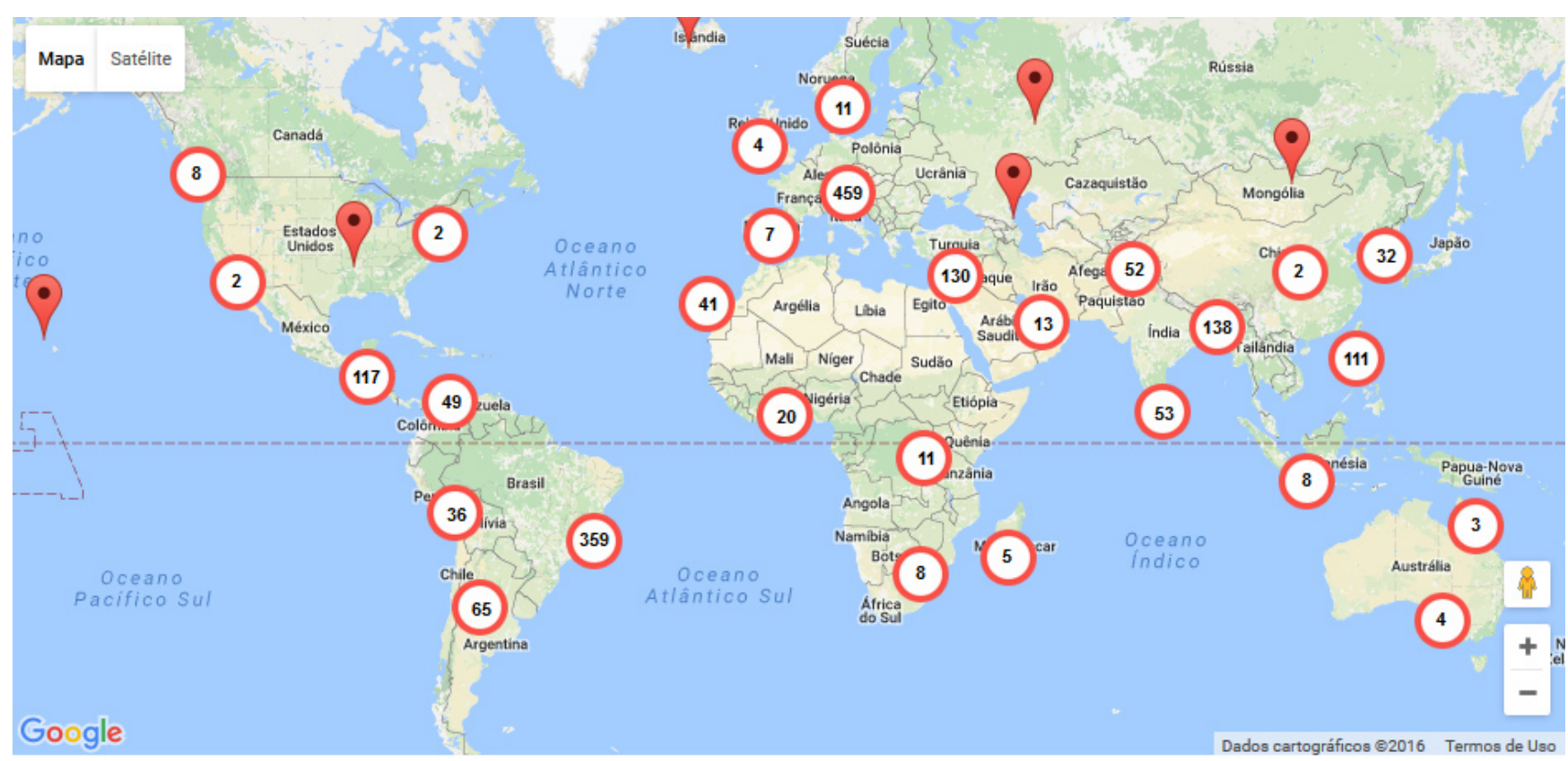

Fonte: UNISDR, 2017. 
Assim, compreendendo que o tema é pauta internacional e que a UNWTO estabeleceu um comitê visando auxiliar seus estados-membro no alcance de um turismo com perspectiva resiliente, compreende-se a premência em canalizar esforços acadêmico-institucionais na intenção de responder à destacada campanha (ONU) e atender ao indicativo da OMT quanto à resiliência das cidades turísticas.

Portanto, para existir um turismo resiliente, devem-se seguir princípios de sustentabilidade enquanto se busca a preparação das destinações turísticas para enfrentar impactos causados por fenômenos naturais, perturbações sociais, crises econômicas e políticas específicas, além do próprio turismo. Dessa maneira, com o fito no "turismo sustentável", empreende-se um "turismo responsável" (Lanzarini \& Barretto, 2014), ultrapassando as barreiras do discurso político para ações mais concretas.

Diante disso, neste estudo que pretende aproximar a resiliência $\mathrm{x}$ turismo, expõem-se a origem e os significados que a resiliência assumiu em tempos contemporâneos. Além disso, reflete-se sobre como as metodologias que examinam o comportamento resiliente de um indivíduo ou ações resilientes para o ambiente (natural e artificial) podem ser incorporadas no turismo no fito do turismo sustentável.

\section{METODOLOGIA}

Para dar suporte a este estudo, realizou-se pesquisa bibliográfica e eletrônica, tendo como pontos de referência preliminar os documentos institucionais oficiais (on-line) da ONU, UNWTO, SOBRARE, MTur e MIN brasileiro.

Além disso, textos científicos que deram suporte para as reflexões e a aproximação entre os temas em tela foram selecionados por meio do processo metodológico ProKnow-C/Knowledge Development Process/Constructivist (Figura 2), desenvolvido por Ensslin et al. (2010), que busca explicitar as etapas da pesquisa estruturada em fases: 
Figura 2: Resumo da seleção do portfólio bibliográfico da metodologia de construção do conhecimento ProKnow-C

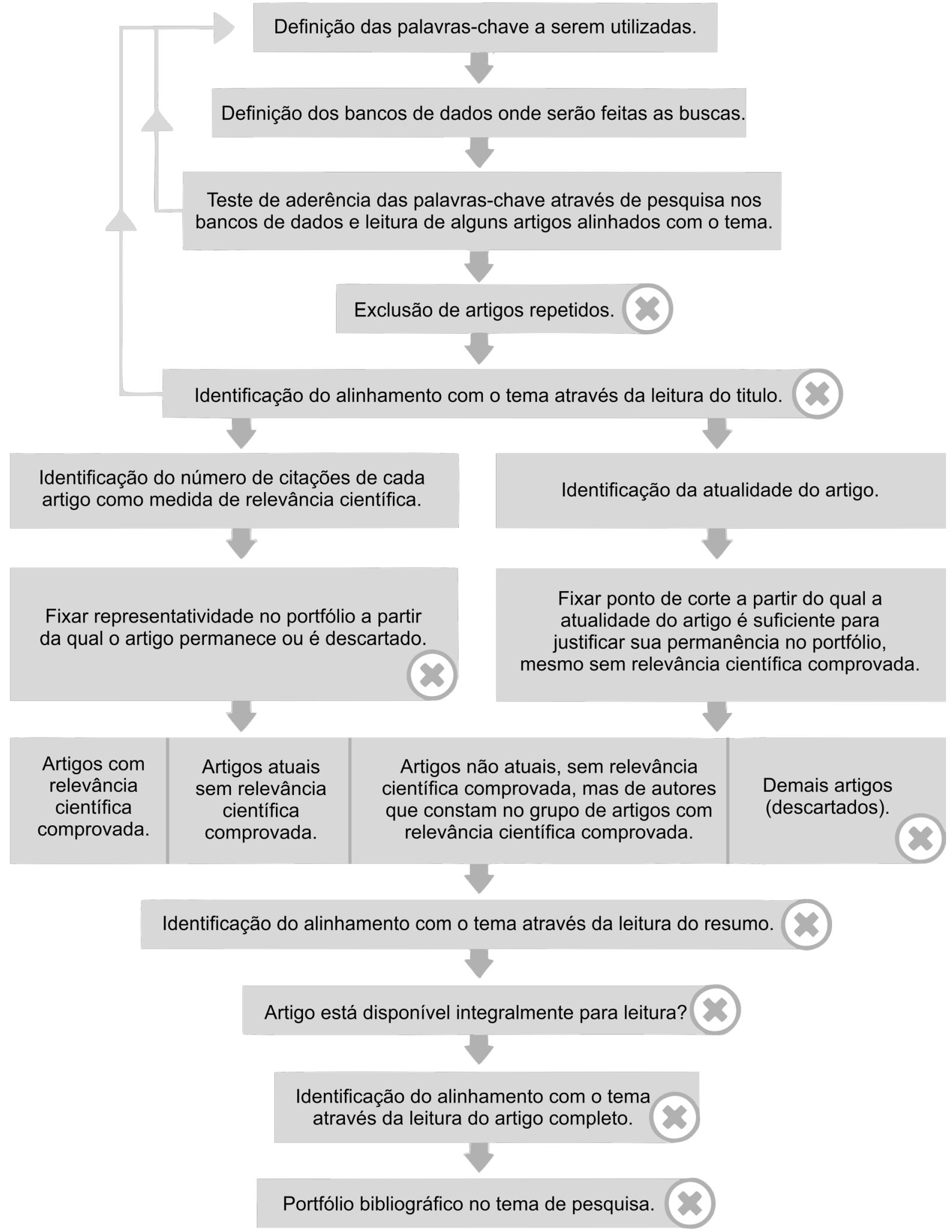

\section{Legenda}

Não obtendo bons resultados, retomar ao ponto inicial
Etapa em que são descartados artigos do portfólio atual.

Fonte: Ensslin et al. (2010). 
Para esta pesquisa foram definidas as seguintes palavras-chave: resiliência, resiliente, turismo, planejamento, organizacional, sustentabilidade, sustentável, (pesquisadas no idioma português e inglês). Tais palavras foram utilizadas nos mecanismos de busca de artigos científicos, isoladamente e combinadas (Afonso et al., 2011) e foi utilizado o repositório de artigos científicos Scientific Periodicals Electronic Library (SPELL), pois concentra produção científica em "Administração, Ciências Contábeis e Turismo" e também o banco de dados do Portal de Periódicos da Coordenação de Aperfeiçoamento de Pessoal de Nível Superior - CAPES (realizada pela plataforma "café" pelos "logins" da UFRN e UNIVALI/Universidade do Vale do Itajaí).

Por meio de tal portfólio, pelo qual se originaram as reflexões iniciais de aproximação temática de temas em estudo, já foi possível verificar que os referidos temas, quando procurados individualmente ou "turismo + planejamento + sustentabilidade/sustentável" e resiliência+organizacional" (combinados), mostram-se abrangentes e muito pesquisados, mas as combinações entre "turismo + resiliente" e também "turismo + resiliência" e/ ou estas combinando com "organizacional", "planejamento" e/ou "sustentab ilidade"/"sustentável" apresentam pouco volume de publicações (Quadro 1 e Gráfico 1).

Quadro 1: Termos de pesquisa em publicação periódica

\begin{tabular}{|c|c|c|c|c|}
\hline \multirow{2}{*}{ TERMOS COMBINADOS } & \multicolumn{2}{|c|}{ SPELL } & \multicolumn{2}{c|}{ CAFe } \\
\cline { 2 - 5 } & Português & Inglês & Português & Inglês \\
\hline Turismo+planejamento & 342 & 286 & 303 & 11688 \\
\hline Turismo+sustentável & 233 & 209 & 276 & 12601 \\
\hline Turismo+sustentabilidade & 195 & 147 & 222 & 4688 \\
\hline Turismo+resiliência & 01 & 01 & 11 & 551 \\
\hline Turismo+resiliente & 00 & 01 & 05 & 250 \\
\hline Turismo+resiliência+planejamento & 00 & 00 & 14 & 66 \\
\hline Turismo+resiliente+planejamento & 00 & 00 & 00 & 18 \\
\hline Resiliência+organizacional & 05 & 09 & 35 & 1213 \\
\hline Turismo+resiliência+organizacional & 00 & 00 & 12 & 02 \\
\hline
\end{tabular}

Fonte: Autoria própria. 
Gráfico 1: Termos de pesquisa em publicação periódica

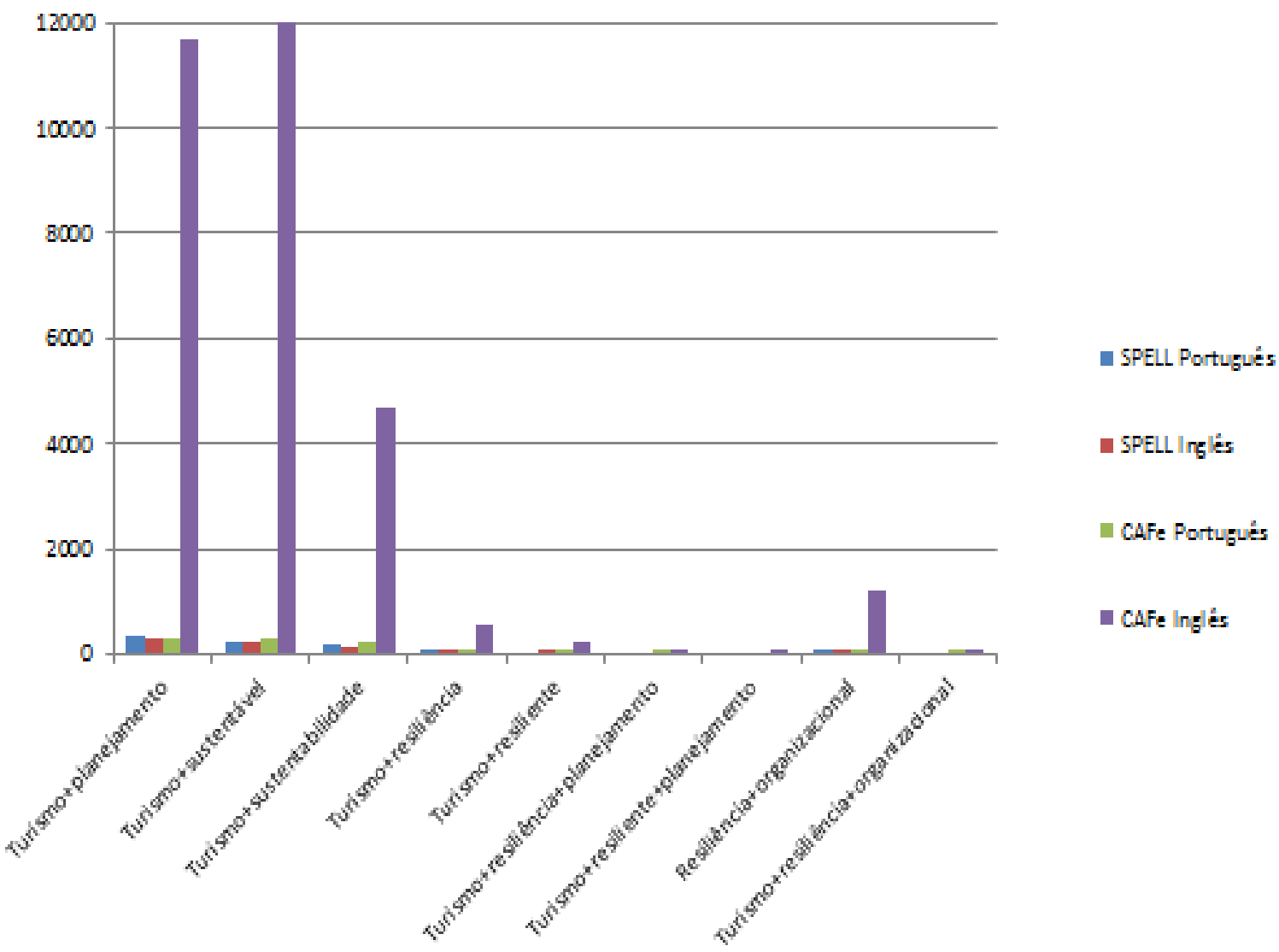

Fonte: Autoria própria.

A partir disso, deu-se continuidade às fases indicadas no ProKnow-C, como segue: exclusão deartigos repetidos ou indisponíveis integralmente; identificação do alinhamento dos artigos pelo título e resumo; identificação da atualidade do artigo; leitura integral dos textos para identificação do alinhamento (por temas) para definição de portfólio bibliográfico específico da pesquisa.

Desta maneira, o portfolio bibliográfico que sustentou as reflexões iniciais foi fixado por eixos temáticos, resultando no seguinte (Quadro 2):

Quadro 2: Portfólio bibliográfico básico da pesquisa

\begin{tabular}{|c|c|}
\hline Eixos Temáticos & Textos/Documentos \\
\hline Abordagem conceitual da resiliência & $\begin{array}{c}\text { Kaplan (1999); Ojeda (2004); Infante (2005); Brandão, } \\
\text { Mahfoud \& Gianordoli-Nascimento (2011); Lemos (2014); } \\
\text { Francisco \& Coimbra (2015). }\end{array}$ \\
\hline $\begin{array}{c}\text { Resiliência humana (comportamento } \\
\text { resiliente) }\end{array}$ & Masten (1999); Barbosa (2011); SOBRARE (2016b). \\
\hline Resiliência organizacional & $\begin{array}{c}\text { Cicchetti \& Becker (2000); Miguel (2012); Dahles \& } \\
\text { Susilowati (2015); Luthar et al (2016); SOBRARE (2016a); } \\
\text { UNWTO (2016). }\end{array}$ \\
\hline
\end{tabular}


Fonte: Autoria própria.

Vale ressaltar que o Quadro 2 apresenta o portfólio básico que foi fixado, considerandooProKnow-Celevou em conta oalinhamentoe a representatividade entre os temas. Além disso, pretende-se realizar a mesma investigação com os termos no idioma espanhol e, então, a avaliação em detalhe das publicações encontradas (por eixo temático) permitirá adensar o debate e será apresentado posteriormente. De posse das informações prévias, já foi possível compor este texto introdutório sobre o turismo e a resiliência (como uma alternativa para a sustentabilidade de localidades turísticas).

\section{FUNDAMENTAÇÃO TEÓRICA}

\section{RESILIÊNCIA}

Durante muito tempo, a concepção de resiliência esteve associada à física e se referia à capacidade dos materiais em absorver as tensões sem se deformar. Até aquele momento, a preocupação científica residia em explicar a "resistência" de diversos materiais, considerando as suas regiões plásticas e elásticas. Então, nas ciências aplicadas e naturais, a "resiliência" integra os estudos a respeito da resistência de materiais e, segundo Timoshenko (1953 apud Miguel, 2012), ela já havia sido utilizada no princípio do século XIX, quando o médico e físico da Inglaterra, Thomas Young, publicou seus estudos relacionados com a elasticidade.

Elwyn James Anthony (psiquiatra infantil), em 1974, elaborou sua pesquisa a respeito da resiliência sobre a saúde e pretendia investigar casos vinculados à vulnerabilidade de crianças que eram filhas de pessoas esquizofrênicas (Miguel, 2012). Nesta pesquisa, as distintas reações observadas nas crianças culminaram na adoção da "resiliência" para designar a capacidade que um indivíduo que é afetado por estresse (ou então pela adversidade) possui em superá-lo e sair fortalecido. Após a divulgação das pesquisas no campo da física e da 
psiquiatria, o tema da "resiliência" passou a ser estudado por outras ciências, tendo como aporte a "capacidade de superação" (Miguel, 2012; Francisco \& Coimbra, 2015).

O estudo Brandão, Mahfoud \& Gianordoli-Nascimento (2011) sobre as origens conceituais acerca da "resiliência" na Psicologia culminou na descoberta de que pesquisadores de diversas localidades do mundo apropriaram-se do tema e o estudam desde diferentes perspectivas. Tais perspectivas foram organizadas por Fantova (2008 apud Brandão, Mahfoud \& Gianordoli-Nascimento, 2011) e Ojeda (2004) em três correntes, como segue:

1) Corrente anglo-saxônica on norte-americana: é uma corrente pragmática, cujo centro do debate é o indivíduo. Toma-se como avaliação sobre a resiliência humana dados quantificáveis e observáveis e, comumente, com o enfoque ecológico transacional ou behaviorista. Nesta corrente, a resiliência emerge como um produto oriundo da interatividade entre o sujeito e o meio em que ele está inserido;

2) Corrente europeia: é uma corrente com perspectiva ética, relativista e, comumente, com enfoque psicanalítico. Toma-se o olhar do sujeito como relevante à avaliação sobre sua resiliência, aonde a resposta do indivíduo às adversidades é "tecida" desde a sua dinâmica psicológica e ultrapassa os fatores do meio, o que propicia uma narrativa mais íntima e externa sobre a sua própria vida;

3) Corrente latino-americana: é uma corrente comunitária que tem seu enfoque social como resposta às dificuldades/problemas do indivíduo em meio às adversidades.

Além da diferença nas perspectivas adotadas por pesquisadores das citadas correntes, há também diferenças no modo de compreender e explicar as origens do assunto, bem como diferenças nos conceitos de resiliência entre os pesquisadores anglo-saxões e os de idioma latino (Brandão, Mahfoud \& Gianordoli-Nascimento, 2011), pois estes de idioma latino (inclusos brasileiros) entendem a concepção de "resiliência" como tomada das ciências naturais (especificamente da área de estudo sobre a resistência de materiais). Já os precursores da temática (norte-americanos e ingleses) não se manifestam sobre 
ISSN: 1983-7151

essa origem. Assim, quanto às concepções já adotadas sobre a resiliência, de maneira geral, norte-americanos e ingleses consideram a resiliência no sentido da "resistência ao estresse", já os brasileiros e os pesquisadores de idioma latino possuem uma concepção sobre a resiliência que ora a considera com o sentido de resistência ao estresse e ora com o sentido associado a processos de superação ou recuperação de abalos psicoemocionais causados pelo stress.

Ainda sobre o desenvolvimento humano, muitos especialistas no estudo da resiliência, no findar do século XX, como Kaplan (1999), Masten (1999), Luthar et al. (2000) e Infante (2005) esclareceram haver acordo na existência de duas gerações de estudiosos sobre o tema, a saber:

a) Primeira geração (anos 1970): o centro do debate estava investigando os sujeitos em situação de risco social e que se adaptavam positivamente, mesmo estando em condições adversas;

b) Segunda geração (anos 1990): incorpora-se ao enfoque da $1^{a}$ geração o estudo relacionado à "dinâmica" entre os fatores que estão na base da adaptação resiliente.

Assim, no início do século XXI, a questão da resiliência assume significações a respeito de um processo mais dinâmico, cujas influências ambientais e do sujeito interatuam em uma recíproca relação que permite ao indivíduo se adaptar, apesar da adversidade (Infante, 2005). Majoritariamente, para a autora, os pesquisadores/estudiosos que pertencem a essa geração simpatizam com o modelo de resiliência ecológico-transacional (com base em Bronfenbrenner, de 1981). Esse modelo consiste no indivíduo encontrar-se imerso em uma ecologia que é determinada por níveis diferentes, que interatuam exercendo influência direta no seu desenvolvimento. Este marco ecológico é formado por níveis, sendo eles: individual, familiar, comunitário (relacionado aos serviços sociais) e o de ordem cultural (relacionado aos valores sociais). Então, ao traduzir tais processos dinâmicos interativos entre os níveis diferentes do citado modelo, poderse-á compreender mais o processo imergido na resiliência. Por consequência, é um desafio para essa geração de estudiosos identificar quais os processos basilares da adaptação resiliente e que possibilitará avançar em termos teóricos e de pesquisa. Além disso, poderá possibilitar a emergência de estratégias com programas dirigidos para promoverem a resiliência e a qualidade de vida. 
Portanto, Infante (2005) distingue três componentes considerados essenciais no conceito/concepção de resiliência:

1) Primeiro componente: noção de adversidade, risco, trauma ou ameaça para o desenvolvimento humano;

2) Segundo componente: superação da adversidade ou adaptação positiva;

3) Terceiro componente: processo que leva em consideração a dinâmica entre os mecanismos socioculturais, cognitivos e emocionais que influenciam o desenvolvimento do ser humano. Por isso, a impactação de um evento adverso, com a adoção de estratégias resilientes, apresenta respostas em três ocasiões distintas: o antes, o durante e o depois (Santos, 2009). Assim, a antecipação, a reação e a recuperação devem ser consideradas maneiras de responder aos eventos dito perturbadores.

\section{COMPORTAMENTO RESILIENTE: A METODOLOGIA DA SOBRARE}

No caso do comportamento resiliente, Reivich e Shatté (2002 apud Barbosa, 2006) observaram que a resiliência (de abordagem cognitiva) é constituída por sete fatores que podem ser mensurados por: administração das emoções, controle dos impulsos, empatia, otimismo, análise causal, autoeficácia e alcance das pessoas. A partir desses fatores é possível determinar o quão resiliente um indivíduo pode ser e onde ele pode melhorar. Esses fatores subsidiaram a tese de doutoramento de George Souza Barbosa em 2006, que adaptou este instrumento para a realidade brasileira e, em 2009, desenvolveu um novo instrumento, a partir de oito modelos básicos de crenças: o "Quest_Resiliência". Por meio dessa escala, pode-se mapear e entender o "quanto" e "de que forma" um indivíduo ou um grupo de pessoas é capaz de superar quando são postas em situações perturbadoras (SOBRARE, 2016b). Com base em um diagnóstico situacional, é possível indicar em quais pontos ou áreas o indivíduo (ou o grupo) precisa melhorar para tornar-se mais resiliente.

Disponibilizado pela SOBRARE no formato on-line na internet, o "Quest_ Resiliência" diz respeito a uma escala que possibilita mapear os índices numéricos em 8 "modelos de crenças determinantes", os quais apresentam os resultados 
em blocos de texto (e ilustrados por gráficos): o primeiro bloco do texto traz uma visão geral da crença; outro bloco traz a descrição dos aspectos relevantes sobre o padrão de respostas naquela crença em particular. Permite verificar em que modelo de crenças se deve apenas fazer a manutenção de fortalecimento por estar com um índice adequado, ou avaliar em qual modelo de crença se necessita fazer um maior investimento (SOBRARE, 2016b).

O "modelo de crenças determinantes" (MCD) da resiliência proposto por Barbosa (2006) se divide em áreas de avaliação, sendo elas: MCD de autocontrole: capacidadeadministraçãoemocional diante doinesperado;MCD deleitura corporal: capacidade de ler e organizar-se no sistema nervoso/muscular percebendo suas próprias mudanças corporais em situações adversas e controlar sintomas dos efeitos do estresse; MCD de otimismo para com a vida: capacidade de manter a esperança, a alegria e os sonhos confiando no gerenciamento das adversidades; MCD de análise do ambiente: capacidade de mapear as causas, as relações e as implicações dos problemas, dos conflitos e das adversidades presentes no ambiente; MCD empatia: capacidade de evidenciar a habilidade de empatia, bom humor e de emitir mensagens que promovam a interação e a aproximação entre as pessoas, mesmo diante de condições perturbadoras/adversas; MCD autoconfiança: capacidade de ter convicção de ser eficaz nas ações propostas; MCD alcançar e manter pessoas: habilidade de construir e manter relacionamentos, conectando-se para a formação de fortes redes de apoio e proteção; MCD sentido de vida: capacidade de entendimento de um propósito vital de vida, fortalecendo e capacitando a pessoa a preservar sua vida ao máximo.

Essas oito áreas subdividem-se em setenta e dois itens a serem pesquisados para avaliar o índice de resiliência de um indivíduo e dizem respeito às crenças do sujeito, versando sobre: controle do comportamento de modo flexível, temperamento, impulso de agir, habilidade para descansar, identificação de consequências nas decisões, prioridades de vida, análise de razões e motivos, capacidade de finalizar tarefas, habilidade de contornar problemas, etc. (Barbosa, 2006). Cada uma dessas áreas representa um conjunto de crenças, ou seja, a forma de acreditar nas coisas que acontecem com os sujeitos, que implicam diretamente o seu comportamento. 
A partir da observação aos MCD's, realizada por meio da análise dos gráficos que são resultantes das respostas dadas a cada um dos itens que integram as oito áreas, bem como do questionário sociodemográfico, Barbosa (2011) menciona que é possível verificar que as crenças não se formam de uma hora para outra. Ao contrário, elas se formam na infância e vêm sendo desenvolvidas junto com o indivíduo durante todas as fases de sua vida. O comportamento expresso após uma situação perturbadora resulta da organização das crenças relacionadas às causas e às implicações daquela situação específica. "Esses modelos comportam os pensamentos negativos (eu não posso, eu não sou capaz, eu não mereço), o desenvolvimento de um discurso interno positivo, de um lócus de controle interno, de uma perspectiva otimista, da assertividade e de competências de resolução de problemas" (Miguel, 2012, p. 51).

\section{AÇÕES PARA REDUZIR RISCOS A DESASTRES NATURAIS:}

CAMPANHA DA ONU

Como já mencionado, o principal direcionamento da Campanha da ONU visando a cidades resilientes (UNISDR, 2012) é para a atuação da governança no intuito de promover a redução de riscos que estiverem vinculados a desastres naturais/catástrofes (inundações, tsunamis, furacões, terremotos e estiagem).

Na campanha (UNISDR, 2012), destaca-se que as cidades e as áreas urbanas representam um sistema denso e complexo de serviços interconexos que, como tal, enfrentam um crescente número de aspectos que conduzem ao risco de desastres. Por conta disso, estratégias e políticas públicas podem ser desenvolvidas para atender cada aspecto como parte de uma visão global para construir cidades de todos os tamanhos e perfis mais resilientes e habitáveis.

Na nominada campanha, entre os principais responsáveis pelos riscos, estão: o crescimento das populações urbanas e o aumento de sua densidade, o que interfere diretamente nos solos e nos serviços, ampliando as ocupações de planícies costeiras ao longo de encostas instáveis e das áreas de risco; a concentração de recursos e capacidade em âmbito nacional, com ausência de fiscalização, recursos humanos e capacidades no governo local, incluindo ordens 
pouco claras para ações de resposta e de redução dos riscos de desastres; a governança local fragilizada e a participação insuficiente dos públicos de interesse locais no planejamento e na gestão urbana; a gestão dos recursos hídricos, dos sistemas de drenagem e dos resíduos sólidos inadequada, causando emergências sanitárias, inundações e deslizamentos; o declínio dos ecossistemas, devido às atividades humanas, tais como a construção de estradas, a poluição, a recuperação das zonas úmidas e a extração insustentável de recursos que comprometem a capacidade de oferecer serviços essenciais, como a proteção e a regulação contra inundações; a deterioração da infraestrutura e dos padrões de construção inseguros, que podem levar ao colapso das estruturas; os serviços de emergência descoordenados, que afetam a capacidade de rápida resposta e preparação; os efeitos adversos das mudanças climáticas que irão, provavelmente, aumentar as temperaturas extremas e as precipitações, na dependência de condições localizadas, com um impacto sobre a frequência, a intensidade e a localização das inundações e outros desastres relacionados ao clima.

Por isso, o documento orientativo da campanha indica os dez passos essenciais para construir cidades mais resilientes (Quadro 3).

Quadro 3: Dez passos para cidades resilientes

\begin{tabular}{|c|c|}
\hline \multirow{10}{*}{$\begin{array}{c}10 \text { passos para } \\
\text { CIDADES } \\
\text { RESILIENTES }\end{array}$} & $\begin{array}{l}\text { 1. Colocar em prática aç̃̃es de organização e coordenação para compreender e aplicar ferramentas de redução de } \\
\text { riscos de desastres, com base na participação de grupos de cidadãos e da sociedade civil. Construir alianças locais. } \\
\text { Assegurar que todos os departamentos compreendam o seu papel na redução de risco de desastres e preparação. }\end{array}$ \\
\hline & $\begin{array}{l}\text { 2. Atribuir orçamento para a redução de riscos de desastres e fornecer incentivos para proprietários em áreas de risco, } \\
\text { familias de baixa renda, comunidades, empresas e setor público para investir na redução dos riscos que enfrentam. }\end{array}$ \\
\hline & $\begin{array}{l}\text { 3. Manter os dados sobre os riscos e vulnerabilidades atualizados. Preparar as avaliações de risco e utilize-as como } \\
\text { base para planos de desenvolvimento urbano e tomadas de decisão. Certificar-se de que esta informação e os planos } \\
\text { para a resiliência da sua cidade estejam prontamente disponíveis ao público e totalmente discutido com eles. }\end{array}$ \\
\hline & $\begin{array}{l}\text { 4. Investir e manter uma infraestrutura para redução de risco, com enfoque estrutural, como por exemplo, obras de } \\
\text { drenagens para evitar inundações; e, conforme necessário investir em ações de adaptação as mudanças climáticas. }\end{array}$ \\
\hline & 5. Avaliar a segurança de todas as escolas e centros de saúde e atualize tais avaliações conforme necessário. \\
\hline & $\begin{array}{l}\text { 6. Aplicar e impor regulamentos realistas, compatíveis com o risco de construção e princípios de planejamento do uso } \\
\text { do solo. Identificar áreas seguras para cidadãos de baixa renda e desenvolva a urbanização dos assentamentos } \\
\text { informais, sempre que possivel. }\end{array}$ \\
\hline & $\begin{array}{l}\text { 7. Certificar-se de que programas de educação e treinamento sobre a redução de riscos de desastres estejam em vigor } \\
\text { nas escolas e comunidades. }\end{array}$ \\
\hline & $\begin{array}{l}\text { 8. Proteger os ecossistemas e barreiras naturais para mitigar inundações, tempestades e outros perigos a que sua } \\
\text { cidade seja vulnerável. Adaptar-se à mudança climática por meio da construção de boas práticas de redução de risco. }\end{array}$ \\
\hline & $\begin{array}{l}\text { 9. Instalar sistemas de alerta e alarme e capacidades de gestão de emergências em seu município, realizando } \\
\text { regularmente exercícios públicos de preparação. }\end{array}$ \\
\hline & $\begin{array}{l}\text { 10. Após qualquer desastre, assegurar que as necessidades dos sobreviventes estejam no centro da reconstrução, por } \\
\text { meio do apoio direto e por suas organizações comunitárias, de modo a projetar e ajudar a implementar ações de } \\
\text { resposta e recuperação, incluindo a reconstrução de casas e de meios de subsistência. }\end{array}$ \\
\hline
\end{tabular}

Fonte: Adaptado de UNISDR (2012). 
Constata-se deste modo que, no referido documento orientativo, para a redução dos riscos aos desastres é necessário o esforço de equipe composta por: governos locais; setores estratégicos (como educação, saúde, transporte, ambiente, etc.); academia, centros de pesquisa; cidadãos, grupos comunitários, incluindo comunidades indígenas e outras populações vulneráveis; setor privado/ negócios comunitários; grupos profissionais, incluindo avaliadores, engenheiros, arquitetos e planejadores; sociedade civil, organizações não governamentais (de base comunitária, de base religiosa, voluntários, etc; autoridades e parlamentares dos governos nacionais; organizações internacionais.

\section{APROXIMAÇÕES ENTRE A RESILIÊNCIA E O TURISMO}

Entendendo que os impactos oriundos do Turismo estão presentes nas localidades com potencial turístico e podem associar-se a outros possíveis eventos perturbadores que pressionam as sociedades receptoras, torna-se relevante a adoção de estratégias resilientes na condução do planejamento e gestão do turismo local. Tais eventos perturbadores, a exemplo de desastres naturais (enchentes, estiagens, furacões, erupções vulcânicas, tsunamis, tornados), exigem das populações residentes respostas eficientes e eficazes, visando resistir, enfrentar, adaptar-se e superar os impactos decorrentes dos fenômenos mencionados.

Então, a noção de trauma, de adversidade, de ameaça ou de risco para o desenvolvimento das pessoas, superação de eventos perturbadores e adaptação positiva leva em consideração a dinâmica entre os mecanismos socioculturais, cognitivos e emocionais que influenciam no desenvolvimento humano (Infante, 2005) e precisam estar presentes em processos antecipativos, reativos e recuperativos nas destinações turísticas, como forma de resposta aos eventos adversos que podem afetar as populações residentes e turísticas.

Assim, em relação ao turismo, podem-se incluir no processo gerenciamento e planejamento dos destinos (antes, durante e depois) protocolos antecipativos, reativos e recuperativos (Figura 3), visando promover e/ou garantir a resiliência dos atores envolvidos (metodologia para conhecer o comportamento resiliente 
das pessoas/profissionais) e da própria localidade turística (metodologias visando à implementação de ações para a resiliência organizacional de localidades suscetíveis a desastres naturais).

Figura 3: Resiliência e Turismo

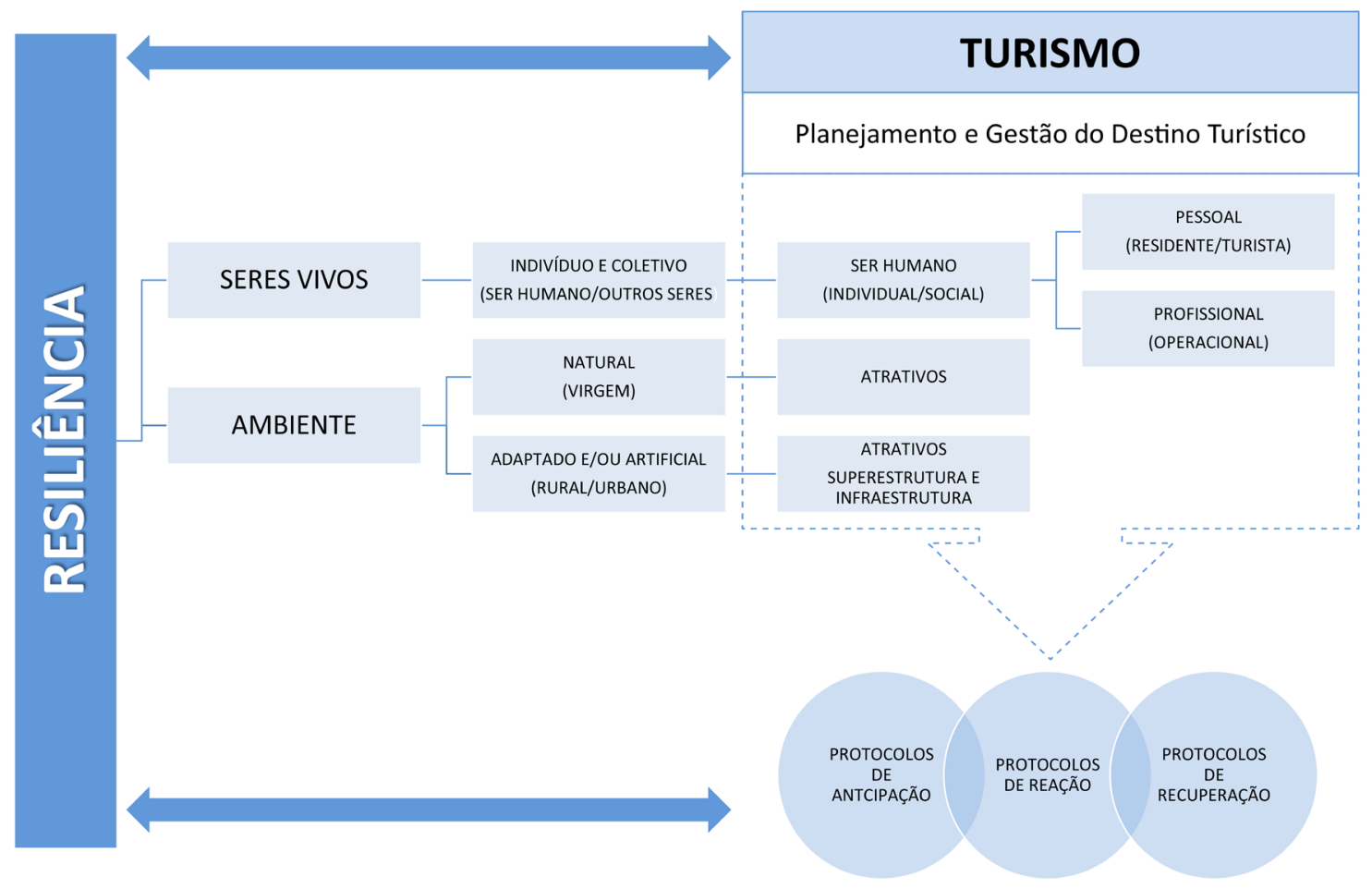

Fonte: Elaboração própria.

Desse modo, ensaia-se a aproximação entre a resiliência e o turismo (figura 3), considerando que as explicações sobre a questão da resiliência sugerem que os objetos de análise focam em dois principais eixos: seres vivos e ambiente.

No caso dos seres vivos referem-se tanto aos seres humanos como a outros seres da natureza e os estudos revelam preocupações com a resiliência individual dos seres e também a coletiva (sociedade). Assim, as preocupações com a resiliência organizacional e a resiliência necessária para resistir, suportar, adaptar e superar adversidades ambientais, sociais, econômicas, políticas e do turismo também são debatidas.

Já sobre o ambiente (natural, adaptado-rural ou artificial-urbano), os estudos advindos das ciências naturais preocupam-se com questões relacionadas às 
especificidades físicas dos materiais e/ou em relação às alterações ocorridas no cenário ambiental, como as oriundas de desastres naturais. Neste caso, as alterações ocorridas também podem advir da estrutura e da dinâmica do próprio turismo, acarretando, por exemplo, a devastação dos recursos naturais e a desestruturação das comunidades locais. A partir desse entendimento, fazse mister também considerar que as localidades turísticas devem ser resilientes ao próprio turismo.

Então, esboçando estratégias baseadas no turismo com abordagem resiliente, pode-se pensar em incorporar, ao menos, duas destas abordagens da resiliência (SOBRARE e UNISDR) para o planejamento e a gestão turística, visando à elaboração de protocolos antecipativos, reativos e recuperativos, a saber:

a) SOBRARE - abordagem que diz respeito à "resiliência organizacional" e também em termos de "comportamento humano" para dar suporte a gestores, empresários, profissionais/colaboradores do setor turístico e de apoio ao turismo, à comunidade local e aos turistas;

Servindo-se da metodologia SOBRARE, torna-se possível analisar o comportamento resiliente dos indivíduos que atuam no setor de negócios/ operacional do turismo (e de apoio ao turismo), bem como no planejamento e na gestão do destino turístico. Assim, pode-se conhecer destes sujeitos, por exemplo: Qual é o seu repertório de "Antecipação" daquilo que pode colocá-lo em situação de estresse quando da sua interação com o turismo? Qual é o seu repertório de "Reação" frente às situações de estresse previstas ou imprevistas quando da sua interação com o turismo? Qual é o seu repertório de "Recuperação" diante das situações de estresse a que foi exposto quando da sua interação com o turismo? Então, a partir da análise destes repertórios, será possível conhecer a situação atual sobre a resiliência deste sujeito, identificar o que é preciso rever e/ ou promover em se tratando de comportamento resiliente e, por fim, estabelecer protocolos para cada etapa (preocupada em antecipar, reagir e recuperar), no intuito de instrumentalizar os atores que interagem no turismo com um referencial teórico-metodológico que promova um turismo mais resiliente.

b) UNISDR - abordagem resiliente que trata da "resiliência de áreas", objetivando ações para reduzir riscos a desastres naturais, em especial nas áreas com intervenção humana, pois para dinamizar o turismo são necessários 
ISSN: 1983-7151

aportes da superestrutura (político) e infraestrutura (básico, apoio e turístico), principalmente nos locais que se consubstanciam em atrativos turísticos.

No caso do turismo e servindo-se do indicado na campanha da ONU, é preciso identificar o papel de cada integrante que deve compor a equipe de trabalho que irá colaborar, planejar, executar e gerenciar as ações propostas pela ONU para a redução do risco de desastres nas cidades turísticas. A partir disso, indicar a inclusão de tais ações no repertório de etapas necessárias ao planejamento e à gestão do destino turístico instrumentalizando, por fim, um referencial teórico-metodológico para o planejamento e gestão de um turismo resiliente, com o fito na sua sustentabilidade.

\section{CONSIDERAÇÕES FINAIS}

$\mathrm{Na}$ intenção de refletir sobre a aproximação entre a resiliência e o turismo e sua possível aplicação no planejamento e na gestão nas localidades turísticas, realizou-se uma pesquisa bibliográfica e documental. Assim, por meio da metodologia Proknow- $C$, mapearam-se textos que permitiram basear as reflexões introdutórias a respeito de tal aproximação temática.

Então, a partir da seleção dos textos, foi possível identificar 4 eixos temáticos, quais sejam: abordagem conceitual sobre a resiliência; resiliência humana (comportamento resiliente); resiliência organizacional; resiliência de localidades/ cidades. A partir disso, considerando a representatividade e/ou o alinhamento entre os temas envolvidos, foram selecionados os textos-base para dar suporte às reflexões acerca da aproximação temática pretendida.

Assim, as reflexões permitiram sinalizar a incorporação de metodologias/ abordagens da resiliência para o planejamento e o gerenciamento do turismo, visando à elaboração de protocolos antecipativos, reativos e recuperativos, a saber: a) abordagem que diz respeito à "resiliência organizacional" e também em termos de "comportamento humano" (gestores, empresários, profissionais/colaboradores do setor operacional e de apoio ao turismo, à comunidade local, aos turistas) e; b) abordagem resiliente que trata da "resiliência de áreas" (principalmente aquelas com intervenção humana), objetivando ações para reduzir riscos a desastres naturais, bem como desestruturações provocadas pelo turismo. 
Tal incorporação, principalmente relacionada ao incluído no guia da ONU para cidades resilientes e à metodologia da SOBRARE para análise do comportamento resiliente no setor operacional do turismo, pode contribuir para transformar as localidades turísticas e os atores que interagem na dinâmica do turismo, mais capazes de atuar em ocasiões de vulnerabilidade e de crises sociais, econômicas, políticas ou ambientais.

Isto porque, servindo-se das metodologias de análise do comportamento resiliente dos sujeitos que participam dos processos turísticos (estrutura, funcionamento e dinâmica), será possível entender e conhecer a sua dimensão resiliente no intuito de poder incentivá-los a desenvolver comportamento/atitudes resilientes no seu modo de vida e/ou atividades profissionais (Barbosa, 2011; SOBRARE, 2016a, 2016b) em ocasiões perturbadoras e de crises (UNWTO, 2016). Além disso, utilizando as metodologias que visam a ações para o incremento da resiliência a desastres na intenção de transformar "cidades resilientes" (UNISDR, 2012), é provável que resulte em "cidades turísticas com resiliência".

É por conta disso que, para incluir a resiliência nos processos gerenciais e de planejamento turístico, é preemente compreendê-la, tanto sobre a análise do comportamento resiliente das pessoas que interatuam nesse processo, como no que diz respeito às ações necessárias para tornar resiliente uma cidade turística. Dessa maneira, será possível fornecer subsídios metodológicos para se planejar e gerenciar o turismo considerando os aspectos fundamentais da resiliência.

Agradecimento: Agradece-se à Fundação CAPES - Coordenação de Aperfeiçoamento de Pessoal de Nível Superior/Ministério da Educação do Brasil, pelo apoio financeiro concedido por bolsa de pós-doutorado.

\section{REFERÊNCIAS}

Afonso, M. H. F.; Souza, J. V.; Ensslin, S. R. \& Ensslin, I. (2011). "Como construir conhecimento sobre o tema de pesquisa? Aplicação do processo ProKnow-C na busca de literatura sobre avaliação do desenvolvimento sustentável". Revista de Gestão Social e Ambiental, 5(2), 47-62.

Amorim, E.; Umbelino, J. \& Costa, C. (2013). "Reflexões sobre a relação entre a educação superior em Turismo com a função de gestão e planejamento dos destinos turísticos". Turismo: Visão e Ação, 15(3), 312-321. 
Anjos, F. A. D.; Anjos, S. J. G. D.; Barros, R. B. \& Zanchi, C. (2005). "Processo de planejamento e gestão de territórios turísticos: princípios norteadores de uma proposta". Turismo: Visão e Ação, 7(2): 377-386

Barbosa, G. S. (2011). "Resiliência e enfermagem: caminhos de superação para o estresse". In: SOCIEDADE BRASILEIRA DE RESILIÊNCIA (SOBRARE). Resiliência e enfermagem: caminhos de superação. São Paulo: SOBRARE (caderno 2).

Barbosa, G. S. (2006). "Resiliência em professores do ensino fundamental de $5^{a}$ a $8^{a}$ Série: Validação e aplicação do questionário do índice de Resiliência: Adultos Reivich-Shatté/Barbosa". Tese (Doutorado em Psicologia Clínica). São Paulo: Pontifica Universidade Católica.

Becken, S. (2013). "Developing a framework for assessing resilience of tourism sub-systems to climatic factors". Annals of Tourism Research, 43, 506-528.

Beni, M. C. (1999). "Política e estratégia do desenvolvimento regional: planejamento integrado e sustentável do turismo". Turismo em Análise, 10(1), 7-17.

Beni, M. C. (2006). "Política e planejamento estratégico no desenvolvimento sustentável do turismo". Turismo em Análise, 17(1), 5-22.

Blandtt, L. da S. (2009). "Da resiliência à sustentabilidade: análise do sistema ecológicosocial em comunidades rurais da Amazônia brasileira". Tese de Doutorado (Doutorado em Desenvolvimento Sustentável do Trópico Úmido) - Programa de Pós-graduação em Desenvolvimento Sustentável do Trópico Úmido, Núcleo de Altos Estudos Amazônicos. Belém: UFPA.

Brandão, J. M.; Mahfoud, M. \& Gianordoli-Nascimento, I. F. (2011). "A construção do conceito de resiliência em psicologia: discutindo as origens". Paidéia, 21(49), 263-271.

Brasil. (2004). "Ministério do Turismo-Programa de regionalização do turismo: roteiros do Brasil". Brasília, DF: Ministério do Turismo.

Brasil. (2007). "Ministério do Turismo- Plano Nacional do Turismo 2007 a 2010: uma viagem de inclusão. Brasília, Ministério do Turismo.

Castro, F. M. M. \& Midlej, M. M. C. (2011). "Planejamento turístico: análise da proposta no município de Valença (BA) no âmbito das recomendações das políticas públicas do turismo no país". Caderno Virtual de Turismo, 11(1), 18-35.

Dahles, H. \& Susilowati, T. P. (2015). "Business resilience in times of growth and crisis". Annals of Tourism Research, 51, 34-50. 
Ensslin, L.; Ensslin, S. R.; Lacerda, R. T. O. \& Tasca, J. E. (2010). "ProKnow-C, Knowledge Development Process-Constructivist". Processo técnico com patente de registro pendente junto ao INPI. Brasil.

Francisco, M. V. \& Coimbra, R. M. (2015). "Resiliência em-si na perspectiva da teoria históricocultural". In: Coimbra, R. M. \& Morais, N. A. (Orgs.) A resiliência em questão: perspectivas teóricas, pesquisa e intervenção. Porto Alegre: Artmed.

Garrod, B. \& Fyal, A. (1998). "Beyond the rhetoric of sustainable tourism?". Tourism Management, 19(3), 199-212.

Hanai, F. Y. \& Espíndola, E. L. G. (2012). "O planejamento e a gestão do turismo sustentável na região de Bueno Brandão (MG/ Brasil)". Caderno Virtual de Turismo, 12(2), 224-238.

Infante, F. (2005). "A resiliência como processo: uma revisão da literatura recente". In: MELILLO, A.; OJEDA, E.N.S. (Eds.). Resiliência: descobrindo as próprias fortalezas. Artmed, São Paulo. Disponível em: http://www.larpsi.com.br/media/ mconnect_uploadfiles/c/a/cap_01ppplo. pdf. Acesso em: 13/06/2016.

Kaplan, H. (1999). "Toward an understanding of resilience: A critical review of definitions and models". In: Glantz, M. \& Johnson, J. (Eds.). Resilience and development: positive life adaptations. New York, Plenum Publishers.

Kim, H. \& Marcouiller, D. W. (2015). "Considering disaster vulnerability and resiliency: the case of hurricane effects on tourism-based economies". The Annals of Regional Science, 54(3), 945-971.

Lanzarini, R. \& Barretto, M. (2014). "Políticas públicas no Brasil para um turismo responsável". Turismo: Visão e Ação, 16(1), 185-215.

Lemos, M. F. (2014). "Sustentabilidade e resiliência". Anais do III Encontro da Associação Nacional de Pesquisa e Pós-graduação em Arquitetura e Urbanismo III ENANPARQ - Arquitetura, cidade e projeto: uma construção coletiva. São Paulo. Disponível em: http://www.anparq.org. br/dvd-enanparq-3/htm/Artigos/ST/ST_AS_003_4_LEMOS.pdf. Acesso em: 13/03/2016.

Luthar, S.; Cicchetti, D. \& Becker, B. (2000). "The Construct of resilience: A critical evaluation and guidelines for future work". Child Development, 71(3), 543-558.

Luthe, T. \& Wyss, R. (2014). "Assessing and planning resilience in tourism". Tourism Management, 44, 161-163.

Masten, A. (1999). "Resilience comes of age: Reflections on the past and outlooks for the next generation of researchers". In: Glantz, M. \& Johnson, J. (Eds.). Resilience and development: positive life adaptations. New York: Plenum Publishers. 
Melo, R. S. \& Brito, A. (2016). "Emisiones de dióxido de carbono de los visitantes de una UC: La unidad de conservación APA del Delta de Parnaíba (Piauí, Brasil)". Estudios y Perspectivas en Turismo, 25(4), 502-519.

Miguel, M. E. G. B. (2012). "Resiliência e qualidade de vida dos docentes de enfermagem". Ribeirão Preto. Tese de doutorado apresentada à escola de enfermagem de Ribeirão Preto/ USP. Universidade de São Paulo.

Mintzberg, H.; Ahlstrand, B. \& Lampel, J. (2010). "Safári de Estratégia: Um Roteiro pela Selva do Planejamento Estratégico". São Paulo: Bookmann.

Monge, J. G. \& Perales, R. M. Y. (2016). "El desarrollo turístico sostenible: Tren Crucero del Ecuador". Estudios y Perspectivas en Turismo, 25(1), 57-72.

Ojeda, E. N. S. (2004). "Introducción: Resiliencia e subjetividad. In: Melillo, A.; Ojeda, E. N. S. \& Rodríguez, D. (Orgs.). Resiliencia y subjetividad: Los ciclos de la vida. Buenos Aires: Paidós.

Orchiston, C.; Prayag, G. \& Brown, C. (2016). "Organizational resilience in the tourism sector". Annals of Tourism Research, 56, 128-163.

Porter, M. (1991). "Towards a dynamic theory of strategy". Strategic Management Journal, $12,95-117$.

Sansolo, D. G. \& Cruz, R. C. A. (2003). "Plano Nacional do Turismo: uma análise crítica". Caderno Virtual de Turismo, 3(4), 1-6.

Santos, F. T. (2009). "Resiliência estratégica para um desenvolvimento regional sustentável". Revista Portuguesa de Estudos Regionais, 20, 29-40.

Silva, N. C., \& Cândido, G. A. (2016). Sistema de indicadores de sustentabilidade do desenvolvimento do turismo: um estudo de caso do município de Areia - PB. Revista Brasileira de Pesquisa em Turismo, 10(3), 475-496.

Sobrare, Sociedade Brasileira de Resiliência. (2016a). "Comportamento resiliente nas organizações". E-book. Disponível em http://sobrare.com.br/wp-content/ uploads/2015/11/ebook-desenvolvendo-uma-cultura-resiliente-nas-organizacoes.pdf. Acesso em: 03/04/2016.

Sobrare, Sociedade Brasileira de Resiliência. (2016b). "Quest_resiliência". Disponível em: http://sobrare.com.br/escala-de-resiliencia/. Acesso em: 02/03/2016.

Solha, K. T. (2006). "Política de turismo: desenvolvimento e implementação". In: Ruschmann, D. \& Solha, K. T. Planejamento turístico. São Paulo: Manole. 
Sonaglio, K. E. (2013). "Transdisciplinar o turismo: um ensaio sobre a base paradigmática". Pasos (Revista de Turismo y Patrimônio Cultural), 11(1), 205-2016.

Unisdr. United Nations International Strategy for Disaster Reduction. (2015). "Marco de Sendai para a Redução do Risco de Desastres 2015-2030". Disponível em: http://www. mi.gov.br/documents/3958478/0/Sendai_Framework_for_Disaster_Risk_Reduction_20152030 +\%28Portugu\%C3\%AAs\%29.pdf/4059be98-843e-49dd-836b-fe0c21e1b664._Acesso em: 13/07/2015.

Unisdr. United Nations International Strategy for Disaster Reduction. (2012). "Como construir cidades mais resilientes: um guia para gestores públicos locais". Genebra: Nações Unidas. Disponível em: http://www.unisdr.org/files/26462_guiagestorespublicosweb.pdf. Acesso em: 11/06/2016.

Unisdr. United Nations International Strategy for Disaster Reduction. (2007). "Hyogo Framework for Action 2005-2015: Building the Resilience of Nations and Communities to Disasters". Geneva: United Nations International Strategy for Disaster Reduction. Genebra: Nações Unidas. Disponível em: https://www.unisdr.org/we/coordinate/hfa. Acesso em: 20/07/2016.

Unisdr. United Nations International Strategy for Disaster Reduction. (2017). "Participating Local Government". Disponível em: http://www.unisdr.org/campaign/resilientcities/home/ cities. Acesso em: 08/05/2017.

Unwto. World Tourism Organization. (2016). "Tourism Resilience Committee Considering Impact of Economic Crisis on Tourism Industry". Disponível em: http://climate-l.iisd.org/ news/unwto-tourism-resilience-committee-considering-impact-of-economic-crisis-ontourism-industry/. Acesso em: 20/03/2016.

Virginio, D. F. \& Ferreira, L. V. (2013). "Gestão pública do turismo: uma análise da política de regionalização no período 2004-2011 no Rio Grande do Norte, Brasil". Caderno Virtual de Turismo, 13(2), 162-182.

\section{CONTRIBUIÇÃO DO AUTOR NA CONSTRUÇÃO DO ARTIGO}

SONAGLIO: Elaboração e correção em conformidade com as exigências da Revista. 